\title{
The Implementation of Modular Distance Learning in the Philippine Secondary Public Schools
}

\author{
${ }^{1}$ Ysthr Rave Pe Dangle, ${ }^{2}$ Johnine Danganan Sumaoang \\ ${ }^{1}$ Montessori Class Directress, British International School of Cambodia, Phnom Penh, Cambodia \\ ${ }^{2}$ College Instructor, University of the Cordilleras, Baguio City, Philippines
}

\begin{abstract}
Face to face learning engagement of students and teachers within the school has been suspended due to the COVID-19 pandemic. This pandemic has paved the way to the implementation of Modular Distance Learning as an urgent response to ensure continuity of education. The Philippines is in the process of adapting to the new normal form of education at present, and continuous innovations of educators and active involvement of other stakeholders are the driving force for its success. The key purpose of this research is to find out the challenges encountered, opinions, and recommendations of teachers, parents, and students in the implementation of Modular Distance Learning in Balbalayang National High School (BNHS) and Baguio City National High School (BCNHS) during the School Year 2020-2021. These challenges, opinions and recommendations were identified through a mixed quantitative and qualitative approach by conducting surveys to the 37 participants in the selected schools through quota and purposive sampling. Deductive thematic analysis was used in the interpretation and coding of data. The main challenges that emerged were lack of school funding in the production and delivery of modules; students struggle with selfstudying, and parents' lack of knowledge to academically guide their child/children. In conclusion, the study was able to determine the prevailing challenges of the participants in terms of resources, preparedness, and communication. The result of this study may serve as a springboard for the future improvements of the schools' existing programs and guidelines on the implementation of modular distance learning.
\end{abstract}

Keywords: Distance learning modalities, modular approach in learning, modular distance learning, Education in COVID-19 pandemic

\section{Introduction}

The outbreak of the new coronavirus infection known as COVID-19 has first occurred at Huanan Seafood Market in Wuhan city of China in December 2019 (Wikipedia, 2020), and within a couple of months it has turned out to be a global health emergency. It has rapidly affected thousands of people, who are sick or being killed due to the spread of this disease. The COVID-19 pandemic also resulted in a widespread disruption such as travel restrictions, closure of schools and global economic recession.

Most countries around the world have temporarily closed educational institutions to contain the spread of the virus and reduce infections (Tria, 2020). Face to face engagement of students and 


\section{3rd International Conference on Advanced Research in Teaching and Education}

teachers within the school has also been suspended. The Philippines is in the process of adapting to the new normal form of education at present, and continuous innovations of educators and active involvement of other stakeholders are the driving force for its success. For the continuity of education and for every school to still attain its mission and vision which is to provide quality education to every Filipino learner, the Department of Education implemented the Modular Distance Learning.

Distance Learning refers to a learning delivery modality, where learning takes place between the teacher and the learners who are geographically remote from each other during instruction. This modality has three types: Modular Distance Learning (MDL), Online Distance Learning (ODL), and TV/Radio-Based Instruction. (Quinones, 2020)

Modular learning is the most popular type of Distance Learning. In the Philippines, this learning modality is currently used by all public schools because according to a survey conducted by the Department of Education (DepEd), learning through printed and digital modules emerged as the most preferred distance learning method of parents with children who are enrolled this academic year (Bernardo, J). This is also in consideration of the learners in rural areas where internet is not accessible for online learning.

The teacher takes the responsibility of monitoring the progress of the learners. The learners may ask assistance from the teacher via e-mail, telephone, text message/instant messaging among others. Where possible, the teacher shall do home visits to learners needing remediation or assistance (Llego, n.d.). Printed Modules will be delivered to students, parents or guardians by the teachers or through the Local Government Officials.

Since education is no longer held within the school, parents serve as partners of teachers in education. Parents play a vital role as home facilitators. Their primary role in modular learning is to establish a connection and guide the child. (FlipScience, 2020).

According to the Department of Education (DepEd), parents and guardians' perform the various roles in Modular Learning such as Module-ator, Bundy-clock, and as Home Innovator. As a Module-ator, they are the ones to get and submit the printed Self-Learning Modules (SLMs) from and to schools or barangay halls at the beginning and end of the week, depending on the agreement between the parents and the school. As a Bundy-clock, they must check their child's schedule or workweek plan. Because of the number of subjects or activities to be done, they must see that it is being followed accordingly to avoid cramming or delays in submission, which may affect the child's performance. Lastly, as a Home Innovator, they must provide their child with a productive learning environment to help them focus more on Learning. It must be a well-lighted and well-ventilated space in the house, with little or no distraction.

The use of modules encourages independent study. One of the benefits of using modules for instruction is the acquisition of better self-study or learning skills among students. Students engage themselves in learning the concepts presented in the module. They develop a sense of responsibility in accomplishing the tasks provided in the module. With little or no assistance from others, the learners progress on their own. They are learning how to learn; they are empowered (Nardo, M.T.B, 2017). Other advantages of modular instruction include more choice and self-pacing for students; more variety and flexibility for teachers and staff; and increased adaptability of instructional materials. 


\section{3rd International Conference on Advanced Research in Teaching and Education}

The disadvantages include greater self-discipline and self-motivation required for students, increased preparation time and lack of concrete rewards for teachers and staff, and greater administrative resources needed to track students and operate multiple modules.

The key purpose of this research is to find out the challenges encountered by the teachers, parents, and students in the implementation of Modular Distance Learning in the Philippine public secondary schools. Also, this study aims to ascertain the methods, interventions or solutions of every educational institutions as well as the government in providing assistance to students, parents and teachers who are having difficulty in this new learning modality.

\section{Methodology}

This study utilized the survey design in determining the challenges on the usage of Modular Distance Learning Modality (MDLM) and descriptive design in identifying the different solutions to these challenges. The opinions and recommendations of students, parents, and teachers were gathered through a survey, particularly by using questionnaires with open-ended questions. The researchers conducted the study in Balbalayang National High School which is located in a rural area of San Gabriel, La Union and Baguio City National High School which is located in an urban area of Baguio City, Benguet. Fifteen (15) students, twelve (12) parents, and ten (10) school personnel in each of the selected school were chosen as key informants through purposive and quota sampling. Emails, Google forms, and social media were used in the distribution of questionnaires and retrieval of data. The questions used in the questionnaires were localized, which was validated by the researchers' research advisor. Deductive Thematic Analysis was used in the interpretation and coding of data.

\section{Results and Discussion}

From the survey, various challenges were encountered by parents, students, and teachers in the implementation of Modular Distance Learning.

Tab.1: Students Group

\begin{tabular}{|l|l|l|l|l|l|l|}
\hline Age & $\mathbf{1 2}$ y/o & $\mathbf{1 3}$ y/o & $\mathbf{1 4}$ y/o & $\mathbf{1 5}$ y/o & $\mathbf{1 7 - 1 8}$ y/o & $17-20$ y/o \\
\hline Year Level & Grade 7 & Grade 8 & Grade 9 & Grade 10 & Grade 11 & Grade 12 \\
\hline No. of students & 9 & 4 & 1 & 2 & 6 & 8 \\
\hline T-n of respondents & 30 & \multicolumn{3}{|l}{} & \\
\hline
\end{tabular}

Table 1 shows the total number of students who participated in this study. Most of the participants are grade 7 which are 9 , followed by $8-12^{\text {th }}$ graders, $6-11^{\text {th }}$ graders, $4-8^{\text {th }}$ graders, $2-10^{\text {th }}$ graders and the least is only $1-9^{\text {th }}$ grader. 
Fig.1: Student's Group

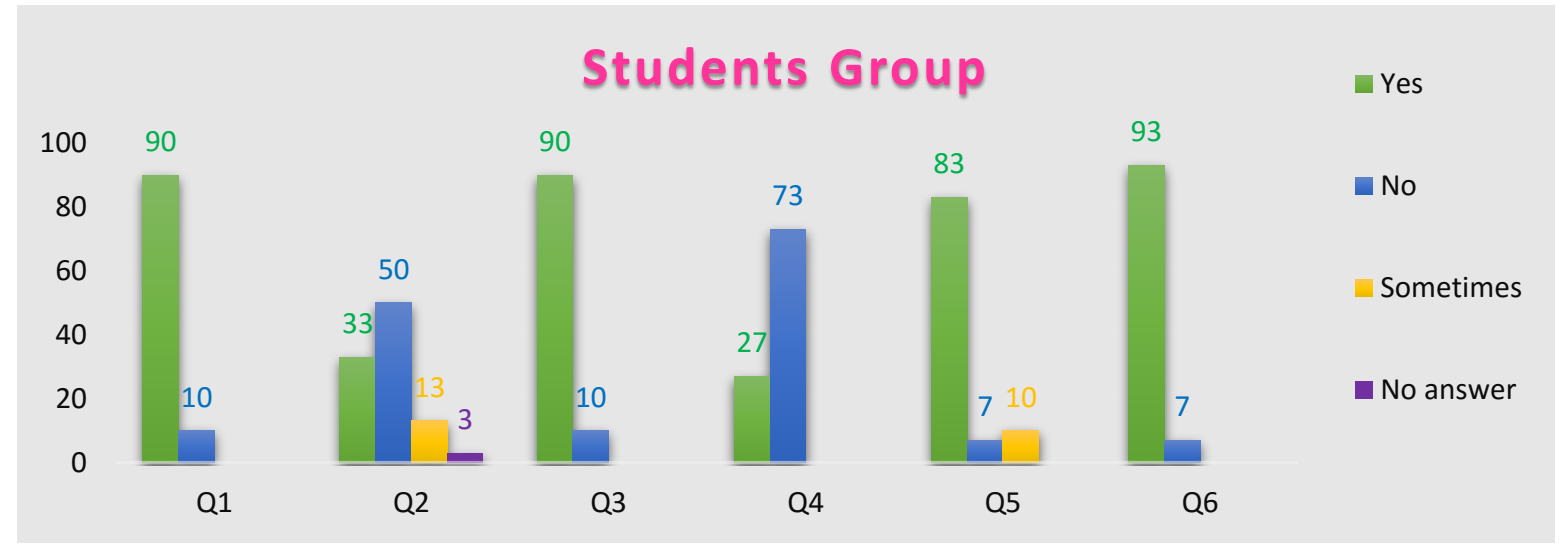

Q1: Are you having difficulty with Modular Distance Learning?, Q2: Do you have enough time to answer all your modules?, Q3: Are you having difficulty in answering your modules?, Q4: Can you answer all your modules on your own?, Q5: Are your teachers approachable?, Q6: Do you have gadget/s to help you answer your modules?

Fig.2: Q7: Do you have a reliable internet connection?
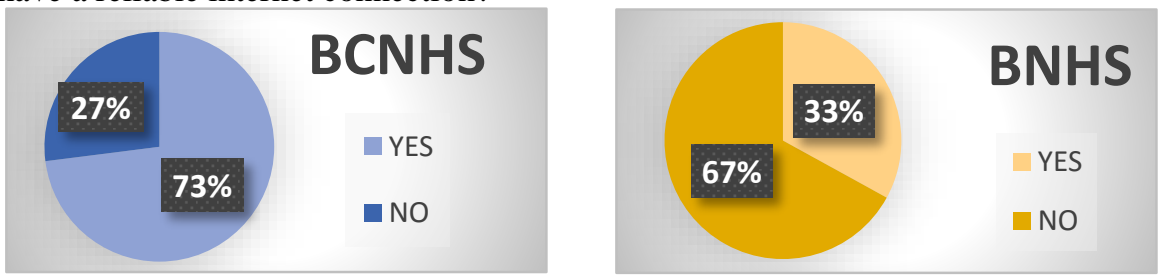

From Fig. 1, it could be seen that most of the learners are having difficulty in this new learning modality. $90 \%$ of the participants had a hard time answering their modules. Half of them do not have enough time to accomplish all their modules within a week. They often receive at least 8 modules in all subjects and each module has 3-5 activities. The subject that they are having greatest difficulty with are Mathematics, followed by History, Entrepreneurship, and Applied Economics. In Mathematics, some students said that most of the Math problems are difficult to solve and no detailed explanation is provided. Problem Solving does not only include and require computation but there is a need to understand and analyze the problem, it is important that students comprehend the problems (Salma \& Rodrigues, 2012). In History, some learners said that this subject has lengthy readings and many of the students cannot understand some of the terms used. The questions are hard as well and there are not enough examples provided. Students have difficulty in understanding the lessons and history books are lengthy (Tok, B. R 2016). Lastly, some students have difficulty in Entrepreneurship and Practical Research because they lack knowledge about business. Furthermore, most of the students cannot answer all their modules independently; that is why they badly need the assistance of others. The family members, relatives and friends of the learners play a vital role in education today. Siblings are at the top of the list helping the learners in answering the modules followed by friends and classmates. Although $83 \%$ of the students said that the teachers were approachable, some said that the teachers do not immediately respond to the queries regarding the lessons. Majority (93\%) of the learners have gadgets that could be useful in learning.

From Fig. 2, 67\% of students in a mountainous area of the Balbalayang National High School (BNHS) do not have a reliable internet connection. On the contrary, $73 \%$ of learners in Baguio City 


\section{and Education}

National High School stated that they have a reliable internet connection. Nevertheless, most of the students from both schools still prefer Modular Learning over Online Learning. Hence, from a total of thirty respondents, twenty-seven of them have chosen Modular Distance Learning. The main challenges that the students have encountered are self-studying, poor internet connection, lack of sleep and time to answer all the modules due to the great number of activities, distractions, and lack of focus.

On the part of the parents, the succeeding tables and figures below show the data gathered from the survey. From Table 2, 21 out of 24 parents have a child enrolled in Grade 7. Likewise, 3 out of 24 parents have a child enrolled in Grade 11.

Tab.2: Parents Group

\begin{tabular}{|l|l|l|l|l|l|l|}
\hline Child's Age & $11-14$ y/o & 13 y/o & 14 y/o & 15 y/o & $16-18$ y/o & $17-20$ y/o \\
\hline Child's Yr. Level & Grade 7 & Grade 8 & Grade 9 & Grade 10 & Grade 11 & Grade 12 \\
\hline Parents' Age & & & & & & \\
\hline $32-54$ & 21 & & & & 3 & \\
\hline T-n of parents & 24 & & & & \\
\hline
\end{tabular}

Fig.3:

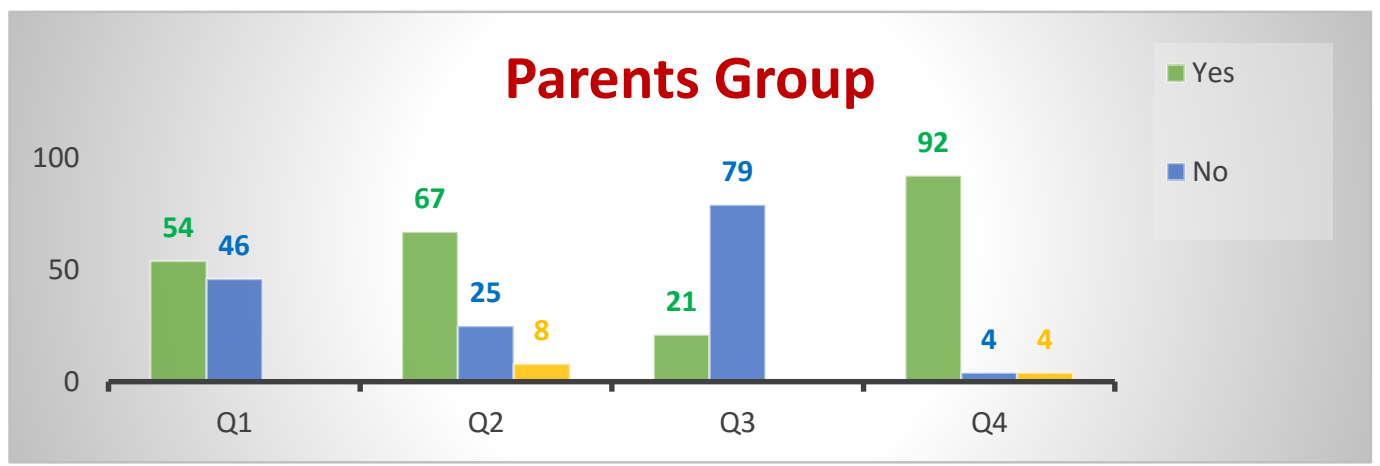

Q1: Are you a working parent? , Q2: Do you have enough time to help your child with his/her modules?, Q3: Are you having difficulty with the set schedule of the retrieval and submission of your child's modules? Q4: Are the teachers of your child approachable?

Figs.4: Q5: Do you have a reliable internet connection?
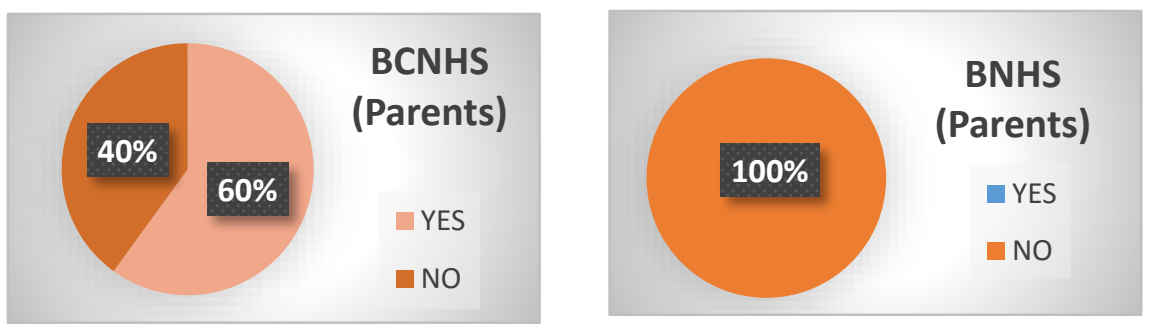

From Fig. 3, 54\% of the parents are working and $46 \%$ are non-working. However, most of them responded that they have enough time to academically assist their child/children in answering their modules. Moreover, $79 \%$ of the parents do not have difficulties with the set schedule of the retrieval and submission of their child's/children's modules. Text, call, and social media particularly on Messenger are the platforms that are being used by the parents to communicate with the teachers of their child/children. Most of them responded that the teachers of their child/children are 
approachable. However, some parents said that some teachers do not respond immediately to their queries and sometimes, they cannot be reached because of low internet connection.

As shown in Fig. 4 above, $60 \%$ of parents in BCNHS have a reliable internet connection whilst $100 \%$ of parents in BNHS do not have a strong internet accessibility. Most of the parents still prefer Modular Distance Learning over Online or Blended Learning because they think that this modular approach is safer for their child/children. This approach is also in consideration for learners living in areas where internet is not accessible. Apart from that, some parents do not have enough gadgets to be used by their child/children for online classes. Some parents have difficulty understanding and answering the modules of their child/children. Some said that they do not have enough time to guide their kids due to work and other responsibilities. Some modules do not have clear instructions and explanations so students have a hard time answering them. The pictures in the modules are not clear and the provided answer lines are too short. The modules have a lot of exercises, and the students lack motivation and focus.

Correspondingly, the following tables and figures show the data gathered from the teachers. A total of 20 teachers participated as key respondents. 10 of them ages 31-40, 6 teachers are 20-30 years old, 2 teachers are 41-50 years old, and 2 teachers ages 51-60.

Tab.3: Teacher's Group

\begin{tabular}{|l|l|l|l|l|}
\hline Teacher's Age & $\mathbf{2 0 - 3 0}$ & $\mathbf{3 1 - 4 0}$ & $\mathbf{4 1 - 5 0}$ & $\mathbf{5 1 - 6 0}$ \\
\hline Frequency & 6 & 10 & 2 & 2 \\
\hline T-n of teachers & 20 & & \\
\hline
\end{tabular}

Fig.5:

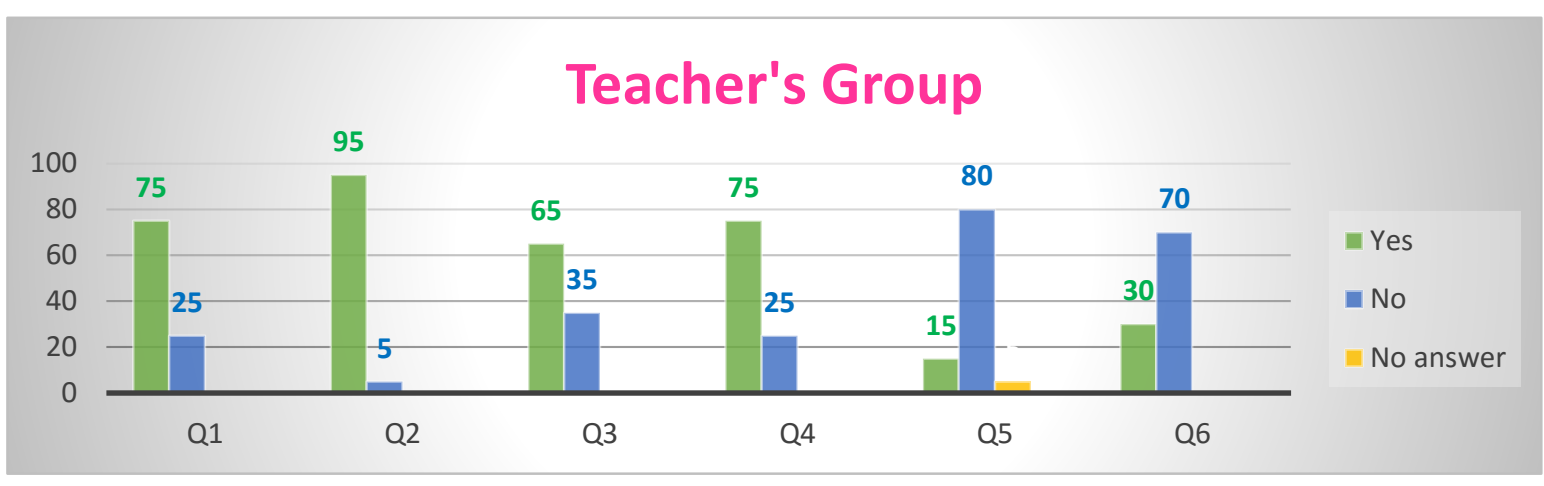

\section{FIGURE 5: Teacher's Group}

Q1: Does DepEd provide all the modules you give to your students?, Q2: Do you see any errors in the modules provided by DepEd?, Q3: Do you have difficulty communicating with parents?, Q4: Do you have difficulty communicating with students?, Q5: Are there enough funds given by the government for Modular Distance Learning?, Q6: Can your students easily follow the instructions in answering the modules?,

Q7: Does your school have a reliable internet connection?

Figs. 6:

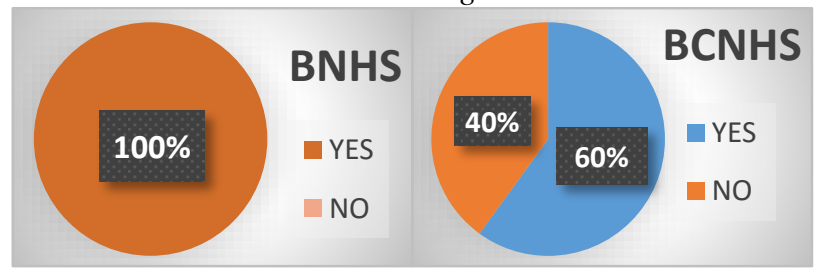

Q8: Do you have a reliable internet connection? Figs. 7:

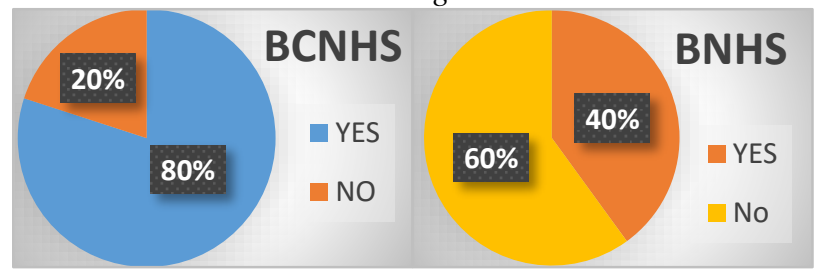




\section{3rd International Conference on Advanced Research in Teaching and Education}

From Fig. 5, 75\% of teachers responded that the Department of Education (DepEd) provides modules for them. However, some of them said that the modules they gave were usually incomplete. 95\% of teachers stated that they noticed errors in the modules and they were permitted to revise the modules with mistakes. Some teachers in some field responded that the central office does not provide modules for their respective subjects which include MAPEH and Journalism-Filipino. Thus, they are the ones making their own modules. $65 \%$ were having difficulty in communicating with parents because some parents do not have cell phones and some cannot afford to buy load all the time. Also, some parents do not reply, some do not respond immediately, and others cannot be contacted. Same as with the students, $75 \%$ of teachers said that it is hard to contact other students because some have numerous social media accounts, some are shy, and some do not have cell phones or gadgets.

From Fig. 6 \& Fig. 7, 60\% of teachers in BCNHS responded that their school has a strong internet connection while all teachers in BNHS said that they do not have a stable internet connection. $80 \%$ of the teachers in BCNHS have their own internet while $20 \%$ said that they do not have. $40 \%$ of teachers in BNHS said that they have their personal Wi-Fi while $60 \%$ of them responded that they do not have their own. Most of the teachers still opt to use Modular Distance Learning over other learning approaches because of poor internet connection as the main reason. In addition, it is accessible and feasible for everyone especially for students in remote areas.

Thus it could be seen from the data that several challenges were encountered by teachers in Modular Distance Learning. Most students cannot study independently. 70\% of them cannot easily follow instructions in the modules. Thus, modules were often submitted late, and most of the answer sheets are blank. Teachers lack resources for reproduction and delivery of modules. Sometimes, the printer is not functioning well. In worst case, sometimes there's no electricity. Therefore, they experience difficulty in printing and mass production of modules. Some learners cannot finish their modules on time because they mostly spend their study time teaching their siblings with their modules and helping their parents in the field. The teachers think that students' answers in their modules have no validity, and most probably, mastery of the lessons is impossible to attain. Parents lack knowledge to assist their child/children. According to some teachers, some parents didn't finish their studies. Some teachers have a weak cellphone signal. Lastly, teachers have a lot of paper works; papers to check and record.

\section{Recommendation}

From the survey conducted, several recommendations were gathered. The methods and strategies suggested by the students to school to further improve the Modular Distance Learning are reduction of activities from the modules, more examples for each subject, home visitation once a week, limited face-to-face class or Blended Learning, provision of coloured printed modules, immediate information given by teachers on what to answer in the modules, online consultation with students, responsiveness of teachers through the use of social media platform, and leniency of teachers in the submission of students' outputs.

The proposed solutions of parents to the identified challenges in Modular Distance Learning are reduce/lessen activities in the modules, take out the unnecessary exercises, Online Learning (a Zoom meeting with the whole class with the teacher going through the modules with the students,

\section{info@icate.org}




\section{3rd International Conference on Advanced Research in Teaching and Education}

answering questions and learning the topics together), simplify the modules, implement blended Learning, consistent instructions in the modules and as much as possible, limit group activities, give each student ample time to complete all the modules, and give more examples and explanations to each of the given activity.

Accordingly, the teachers said that donations, solicitations, and assistance of PTA and other stakeholders were some of the ways to augment the financial needs of the school; the government must make the modules as textbooks, and the DepEd must allocate additional funds for modules. The appropriate interventions to be provided for struggling learners according to teachers are consistent consultation through text, call, and through other social media platforms, organization of Community Learning Facilitators (CLF), home visitation for direct tutorials, simplification of modules, and immediate note/feedback made by teachers which are written in vernacular language. For parents, teachers can give them assistance through text and call, community facilitating, consultation and posting updates on social media, and by giving them words of encouragement.

\section{Conclusion}

The great number of activities in each module is one of the main problems that emerged in the implementation of Modular Distance Learning. The Department of Education should consider this problem, reduce the activities, and take out the unnecessary topics so that mastery will be attained as much as possible. As what some of the parents said, the lesser the better. One of the concerns of the students is that they do not have enough time to answer all the modules within a week. Therefore, if DepEd cannot extend the duration of accomplishing the modules, they must lessen the activities. We all know that mistakes cannot be avoided at times. Thus, teachers should re-evaluate the modules, and they must make sure that all the lessons or activities are appropriate to the needs of the learners. The parents, as well as the students, are right; the instructions in every exercise must be clear enough for the learners to understand. The topics must be simplified, and teachers must give more examples. Moreover, all the printed pictures in the modules should be clear. The cases of COVID-19 in the Philippines are still in great number, so face to face learning is not yet possible. However, the researchers think that Blended Learning is also possible for places that are not infected by the virus. This can be applied to some schools located in rural areas like BNHS. Online Learning approach could be implemented in urban areas like BCNHS since most of the learners have an internet connection. For the students who still cannot access the internet, they will be given special consideration by home visitation as an example. Aside from text and call, social media particularly on messenger is one of the most used modes of communication between teachers, parents, and students. Therefore, teachers are recommended to be active online most of the time. They must be able to address the sentiments of some parents and students, which is to be patient enough in attending to the needs and to respond to the queries immediately with regards to learning. The Department of Education and the government must collaborate together towards the success of Philippine Educational System despite the COVID-19 pandemic. It is imperative that every school must be provided with support and enough funds. The Department of Education should give autonomy and freedom to teachers in every school to do their own modules. However, the modules must be validated for the quality assurance and the progress will be monitored. 


\section{3rd International Conference on Advanced Research in Teaching and Education}

\section{Acknowledgment}

This paper is an output of the researchers in Methods of Research for the Degree of Masters of Arts in Education at the University of the Cordilleras, Baguio City, Philippines.

First of all, we would like to thank our advisors, Dr.Thelma Palaoag and Dr. Ramir Austria for the assistance to complete this journal successfully.

We also would like to express our appreciation to Ms. Jenifer Ammugauan, Sir Fernando Oringo, and Sir Israel Sung-ag for providing insights and suggestions.

Likewise, thank you Ma'am Carmelita Dangle and Sir Jeramy Ballesteros of Balbalayang National High School and Ma'am Joy Altiyen of Baguio City National High School for the support in the distribution of questionnaires to the participants.

To all the key informants who took part in this study, we appreciate all your help!

\section{References}

Quinones, M. T. (2020, July 3). DepEd clarifies blended, distance learning modalities for SY 20202021. Philippine Information Agency. https://pia.gov.ph/news/articles/1046619

Tria, J. Z. (2020, June 3). The COVID-19 Pandemic through the Lens of Education in the Philippines: The New Normal. ResearchGate. https://www.researchgate.net/publication/341981898_The_COVID19_Pandemic through the Lens_of_Education_in the_Philippines_The_New_Normal

Wikipedia contributors. (2020, October 30). COVID-19 pandemic. Wikipedia. https://en.wikipedia.org/wiki/COVID-19_pandemic

Bernardo, J. (2020, July 30). Modular Learning most preferred parents: DepEd. ABS-CBN News. https://news.abs-cbn.com/news/07/30/20/modular-learning-most-preferred-by-parentsdeped

FlipScience. (2020, October 5). 'Tagapagdaloy': How Filipino parents can help ensure successful modular distance learning. FlipScience - Top Philippine Science News and Features for the Inquisitive Filipino. https://www.flipscience.ph/news/features-news/tagapagdaloymodular-distance-learning/

Llego, MA. (n.d). DepEd Learning Delivery Modalities for School Year 2020-2021. TeacherPh. https://www.teacherph.com/deped-learning-delivery-modalities/

Nardo, M. T. B. (2017, October 20). Modular Instruction Enhances Learner Autonomy. Sciepub.http://pubs.sciepub.com/education/5/10/3/index.html\#:\%7E:text=The\%20use $\% 20$ of $\% 20$ modules $\% 20$ is,in $\% 20$ doing $\% 20$ their $\% 20$ individual $\% 20$ tasks.\&text=It $\% 20$ directs $\%$ 20students\%20to\%20practice\%20or\%20rehearse\%20information.,To\%20gain\%20mastery

\section{info@ic a t e . org}

